\title{
Functionalized cork-polymer composites (CPC) by reactive extrusion using suberin and lignin from cork as coupling agents
}

\author{
Emanuel M. Fernandes ${ }^{\mathrm{a}, \mathrm{b}, *}$, Ivo M. Aroso ${ }^{\mathrm{a}, \mathrm{b}}$, João F. Mano ${ }^{\mathrm{a}, \mathrm{b}}$, José A. Covas ${ }^{\mathrm{c}}$, Rui L. Reis ${ }^{\mathrm{a}, \mathrm{b}}$ \\ a 3B's Research Group - Biomaterials, Biodegradables and Biomimetics, University of Minho, Headquarters of the European Institute of Excellence on Tissue Engineering \\ and Regenerative Medicine, AvePark, 4806-909 Taipas, Guimarães, Portugal \\ b ICVS/3B's - PT Government Associate Laboratory, Braga/Guimarães, Portugal \\ ${ }^{\mathrm{c}}$ Institute for Polymers and Composites/I3N, University of Minho, 4800-058 Guimarães, Portugal
}

\section{A R T I C L E I N F O}

\section{Article history:}

Received 7 February 2014

Received in revised form 11 July 2014

Accepted 25 July 2014

Available online 1 August 2014

\section{Keywords:}

A. Polymer-matrix composites (PMCs)

B. Fibre/matrix bond

D. Electron microscopy

E. Extrusion

Coupling agent

\begin{abstract}
A B S T R A C T
High density polyethylene (HDPE) and cork powder were compounded in a co-rotating twin-screw extruder to obtain cork-polymer composites (CPC) with improved properties. Benzoyl peroxide (BPO) was used as initiator agent, and suberin or lignin isolated from cork enhanced filler-matrix bonding and promoted mechanical reinforcement with environmental benefits. The novel composites were characterised in terms of dimensional stability, evolution of morphology, thermal and mechanical properties and their performance was compared with that of composites containing polyethylene-grafted maleic anhydride (PE-g-MA) as coupling agent. As expected, composites with coupling agent present higher mechanical properties, lower water uptake and thickness swelling variation. Suberin acts as plasticizer with antioxidant benefits, while lignin works as a coupling agent, improving tensile modulus and maximum strength. Increasing lignin content does not improve the mechanical properties but improves thermal stability.
\end{abstract}

(c) 2014 Elsevier Ltd. All rights reserved.

\section{Introduction}

The use of synthetic polymers combined with lignocellulosic materials has become a reliable alternative to develop new sustainable materials with good performance and reduced cost [1-3]. Cork is the outer bark of the Oak tree Quercus suber L. [4], where the harvesting of cork is a natural, renewable process that reduces subsequent carbon footprints. During industrial cork processing, up to $30 \%$ results in sub-products such as cork powder, which is used in small amounts low value added applications. Cork-polymer composites (CPC) are usually prepared through melt based technologies. Increasing the percentage of cork in the composite without compromising the overall properties is seen as a desirable route towards sustainability. However, commodity thermoplastic matrices, such as polyethylene and polypropylene, are chemically incompatible with lignocellulosic materials, requiring the incorporation of coupling agents to improve interfacial adhesion [1,5]. The addition of functionalized polymers containing

\footnotetext{
* Corresponding author. Address: 3B's Research Group - Biomaterials, Biodegradables and Biomimetics, University of Minho, AvePark, Zona Industrial da Gandra, 4806-909 Caldas das Taipas, Portugal. Tel.: +351 253 510900; fax: +351253 510909.

E-mail address: efernandes@dep.uminho.pt (E.M. Fernandes).
}

maleic anhydride (MA) groups during compounding showed to be an effective method to improve interfacial bonding, even when using different cork qualities [6-8]. The typical chemical composition of cork is about $40 \%$ of suberin, up to $22 \%$ of lignin, $18 \%$ of polysaccharides and up to $15 \%$ of other extractives [4,9]. Suberin and lignin are thus the main constituents and in combination with a closed cellular morphology account for cork's unique properties, namely excellent insulation characteristics, low density and permeability, low thermal conductivity, high energy absorption, resilience, near-zero Poisson coefficient and high friction coefficient $[9,10]$. Suberin is a natural biopolymer typically found in the cell walls of plants [11]. Cork suberin is constituted by a polyester structure of long chain fatty acids, hydroxyl and phenolic acids, linked by ester groups, with ferulic acid acting as a bridge between the aromatic and the aliphatic domains [12-14]. Whether the aromatic domain is part of the suberin molecule is still a matter of debate [15]. The alkaline depolymerisation in an organic solvent results in the release of the aliphatic constituents through cleavage of the ester linkages and transesterification [13,16,17]. Full characterisation of cork lignin is still incomplete because of the complex relation between true lignin and the aromatic fraction of suberin. Nevertheless, Marques et al. [18-20] found that cork is composed of a $\mathrm{G}$ type lignin with 94-96\% guaiacyl, less than 3-5\% syringyl and 2-3\% hydroxyphenyl units [21]. A comprehensive review on 
cork structure and chemical composition can be found in Silva et al. [9] and references within. In a previous study, the potential of suberin and chemically modified suberin to promote adhesion between low density polyethylene and cork was demonstrated [22]. Lignin has been proposed to reinforce the mechanical properties of composites [23-25], to promote adhesion in natural fibre composites [26], or, in combination with a coupling agent, to improve mechanical performance [24,27]. In all cases, high amounts of lignin or the addition of a coupling agent were necessary to reinforce the composites.

This work focus on the development of cork-polymer composites (CPC) using suberin and lignin as bio-based coupling agents through a reactive extrusion (REX) process, in order to overcome with environmental benefits the insufficient adhesion between cork and a high density polyethylene (HDPE) matrix. REX has the capability of functionalize, prepare the composite and produce pellets in a single step. No environmental or health hazardous solvents are used, low investment costs and high production yields are obtained [21,28]. Initiators are usually required, the most widely used in grafting reactions being organic peroxides, including benzoyl peroxide (BPO). The work investigates for the first time: (i) the evolution of morphology during the compounding process; (ii) the dimensional stability and thermal properties of the composites; (iii) the effect of suberin, lignin, and initiator agent on the tensile properties. These properties are compared with those of an equivalent system using a coupling agent based on maleic anhydride (PE-g-MA).

\section{Materials and methods}

\subsection{Materials}

Cork powder, with an average particle size $<500 \mu \mathrm{m}$, a specific weight of $157 \pm 2 \mathrm{~kg} \mathrm{~m}^{-3}$ and a humidity of $\sim 5.4 \%$ was supplied by Amorim Revestimentos S.A. (Oleiros, Portugal). The matrix was a high density polyethylene HDPE, (HMA - 025 from ExxonMobil, Germany), with a MFI of $8.2 \mathrm{~g} .10 \mathrm{~min}^{-1}\left(190^{\circ} \mathrm{C}, 2.16 \mathrm{~kg}\right)$, and a melting point of $136.6{ }^{\circ} \mathrm{C}$, containing a thermal stabilizer. HDPE grafted with maleic anhydride (PE-g-MA), containing $0.5-1.0 \mathrm{wt} . \%$ of maleic anhydride (Exxelor PE 1040), with MFI of $1.4 \mathrm{~g} .10 \mathrm{~min}^{-1}\left(190{ }^{\circ} \mathrm{C}\right.$, $2.16 \mathrm{~kg}$ ), and having a melting point of $131.3^{\circ} \mathrm{C}$, was produced by ExxonMobil, Germany. Benzoyl peroxide (BPO, 75\%), USP grade, Luperox ${ }^{\circledast}$, was obtained from Atofina Chemicals. The compositions prepared are presented in Table 1. The cork-polymer (20-80) wt.\% ratio was maintained in all formulations.

\subsection{Extraction of suberin and lignin}

Extractive free cork powder was obtained after three consecutive $6 \mathrm{~h}$ soxhlet extractions with dichloromethane, ethanol and

\section{Table 1}

Compositions of the cork-polymer composites (CPC) using suberin and lignin and maleic anhydride as coupling agent.

\begin{tabular}{lllllll}
\hline & \multicolumn{7}{l}{ CPC composition $(w t . \%)$} \\
\cline { 2 - 7 } Sample & HDPE $^{\mathrm{a}}$ & Cork & BPO $^{\mathrm{b}}$ & Suberin & Lignin & PE-g-MA $^{\mathrm{C}}$ \\
\hline CPC1 & 80.0 & 20.0 & - & - & - & - \\
CPC2 & 80.0 & 20.0 & - & - & - & 2 \\
CPC3 & 77.6 & 19.4 & 1 & 2 & - & - \\
CPC4 & 77.6 & 19.4 & 1 & - & 2 & - \\
CPC5 & 76.0 & 19.0 & 1 & - & 4 & - \\
CPC6 & 76.0 & 19.0 & 1 & - & 4 & - \\
CPC7 & 79.2 & 19.8 & 1 & - & - & - \\
\hline
\end{tabular}

a HDPE - high density polyethylene.

b BPO - benzoyl peroxide.

c PE-g-MA - coupling agent based on maleic anhydride, with a level content of $0.5-1.0$ wt.\%. water. The resulting material was used to obtain the suberin and lignin fractions. Suberin extraction procedure was adapted from Ekman and Eckerman [29] and Pinto et al. [30]. The product (1 g to $13 \mathrm{ml}$ ) was refluxed in ethanol:water $(25: 1)$ containing $0.5 \mathrm{M}$ sodium hydroxide for a period of $6 \mathrm{~h}$. After cooling, the resulting mixture was filtered and the liquid fraction was acidified to $\mathrm{pH}$ 5-6 with hydrochloric acid. After filtration, the solvent was removed in a vacuum evaporator. The resulting solid residue was suspended in water and extracted with 3 times the volume in chloroform. The organic fraction was recovered and the solvent removed in a vacuum evaporator, resulting in a brownish paste-like material.

The methodology for lignin extraction was adapted from Ekman and Eckerman [29] and Browning [31]. The solid residue resulting from the suberin extraction was thoroughly washed with distilled water until neutral $\mathrm{pH} .350 \mathrm{ml}$ of a $72 \%$ sulphuric acid solution were added to $30 \mathrm{~g}$ of this residue and the mixture was maintained under agitation for $2 \mathrm{~h}$ at room temperature, followed by the addition of $550 \mathrm{ml}$ of distilled water and refluxing for $4 \mathrm{~h}$. After cooling to room temperature, the solid residue was recovered through filtration and washed with distilled water until neutral $\mathrm{pH}$, a dark powdery material being obtained.

\subsection{Twin-screw compounding}

Before compounding, the cork powder was pre-dried at $80^{\circ} \mathrm{C}$ in a vacuum oven until constant weight. The raw materials, including the pulverized polyethylene, the benzoyl peroxide (BPO) and PE-gMA, were pre-mixed. Compounding was performed in a prototype modular laboratorial mini intermeshing co-rotating twin-screw extruder (TSE), with a screw diameter of $13 \mathrm{~mm}$, and a length to diameter ratio $(\mathrm{L} / \mathrm{D})=27$, coupled to a rod die with a diameter of $3 \mathrm{~mm}$. The screw profile is built by sliding along a shaft conveying and kneading elements with a maximum channel depth of $1.5 \mathrm{~mm}$. As seen in Fig. 1, the configuration used in the experiments induces polymer melting in the first restrictive block upstream and dispersive and distributive mixing in the second kneading block, which comprises 8 discs staggered at $-30^{\circ}$. The extruder is provided with sampling devices along its length which are capable to collect in circa 1 second small amounts of material from within the screw channel [32]. This allowed to obtain cork-polymer samples at locations A and B identified in Fig. 1, i.e., where most of the dispersive mixing action should take place. The temperature profile along the barrel and die was set to $165 / 180 / 185 / 185 / 175^{\circ} \mathrm{C}$ for all the experiments, the feed rate was kept at $130 \mathrm{~g} \mathrm{~h}^{-1}$, and the screws rotating at 70 rpm. Fig. 2 shows the compounding methodology adopted. Due to the low density and high volume of cork powder fraction, the pre-mixed polymer and cork were feed upstream (position 1) by a miniaturized volumetric feeder (based on a Moretto DVM $18 \mathrm{~L}$ ), together with the BPO initiator, or the PE-g-MA. Suberin and or lignin were added in position 2, by means of an automatic syringe pump (AL-1000, from WPI, USA), or manually, respectively. After air-cooling, part of the extruded composite was pelletized.

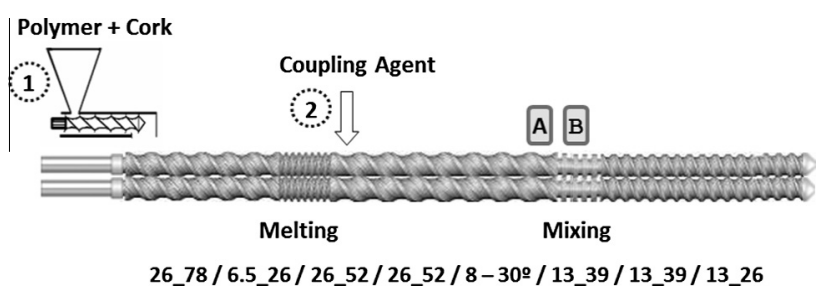

Fig. 1. Twin-screw extruder set up. Screw profile is defined in terms of (pitch_length) of the various elements. A and B denote locations of material sampling. 


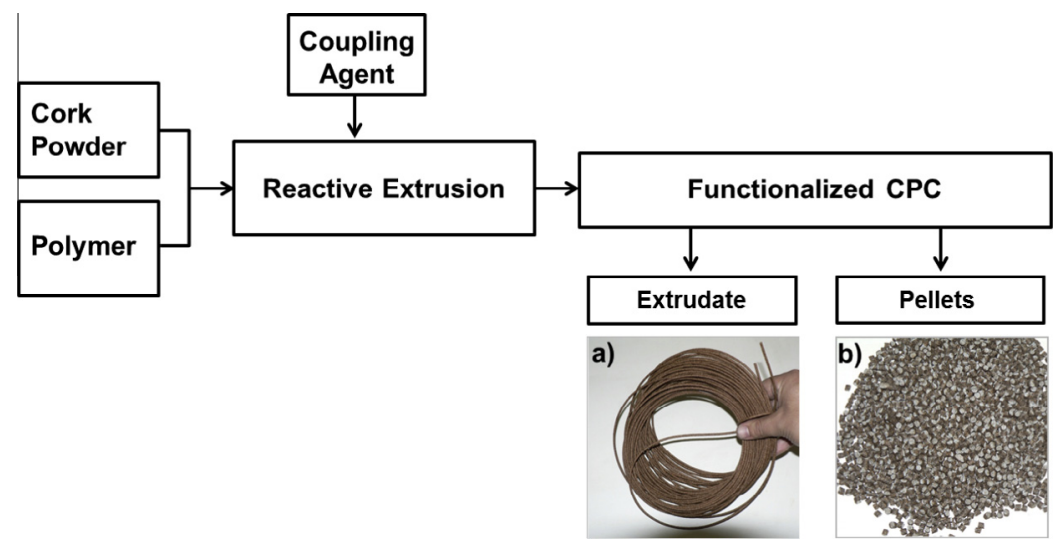

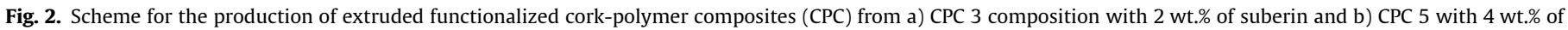
lignin as coupling agent in the pellet form.

\subsection{Chemical characterisation}

Suberin and lignin were analysed by Fourier transform infrared (FTIR) spectroscopy. The spectra were acquired between $4000 \mathrm{~cm}^{-1}$ and $500 \mathrm{~cm}^{-1}$ in a Shimadzu IR-Prestige 21 spectrometer, as the average of 32 scans with a resolution of $4 \mathrm{~cm}^{-1}$. Suberin and Lignin spectra were obtained using the $\mathrm{KBr}$ pellet technique and cork spectra were recorded using the attenuated total reflectance (ATR) module (PIKE Technologies).

\subsection{Thermal properties}

The thermal stability of cork and of its major isolated chemical fractions was determined using a TGA Q500 Thermogravimetric Analyser (TA Instruments, USA). Experiments were performed at a heating rate of $10^{\circ} \mathrm{C} \mathrm{min}{ }^{-1}$ from $50{ }^{\circ} \mathrm{C}$ to $600{ }^{\circ} \mathrm{C}$ under air atmosphere. All tests were repeated once.

Differential scanning calorimetry (DSC) and oxidation induction time (OIT) measurements were performed in a TA instrument DSC Q100 model (USA) instrument on samples of 8-12 mg, at a heating rate of $10^{\circ} \mathrm{C} \mathrm{min}^{-1}$, under nitrogen atmosphere (flux of ca. $\left.50 \mathrm{ml} \mathrm{min}^{-1}\right)$. Only the second run was analysed for melting temperature $\left(T_{m}\right)$ and melting enthalpy $\left(\Delta H_{m}\right)$. The degree of crystallinity was calculated on the basis of a $100 \%$ crystalline PE a melting enthalpy of $\Delta H m^{\circ}=293 \mathrm{~J} \mathrm{~g}^{-1}$ [33]. The analyses were performed in two samples of each condition.

OIT measurements were conducted in the same equipment, with samples heated at a rate of $30^{\circ} \mathrm{C} \mathrm{min}^{-1}$ up to $200{ }^{\circ} \mathrm{C}$ under nitrogen atmosphere. After $2 \mathrm{~min}$ at $200{ }^{\circ} \mathrm{C}$ the atmosphere was changed to pure oxygen (both gases at flux $50 \mathrm{ml} \mathrm{min}^{-1}$ ) and oxidation induction time was measured during the isothermal period. The analyses were performed in three samples of each condition.

\subsection{Scanning electron microscopy}

Fractured samples of the various composites were examined in a NanoSEM 200 FEI (The Netherlands) scanning electron microscope (SEM). Prior to the analysis, samples were coated with an $\mathrm{Au} / \mathrm{Pd}$ alloy (80-20 wt.\%) by ion sputtering in a high resolution sputter coater (Cressington 208HR, Watford, UK).

\subsection{Mechanical properties}

Three millimetre thick plaques were obtained by compression moulding in a hot press (Moore, UK) of the pellets of the various compositions at $150{ }^{\circ} \mathrm{C}$ under an applied pressure of $1.42 \mathrm{MPa}$.
The pellets were kept during a period of 8 min without pressure and 2 min with pressure, followed by a cooling period under pressure. Tensile specimens with dog bone shape according to ISO 527-2 (with a cross-section of $3 \times 4 \mathrm{~mm}^{2}$ at the neck) were machined by a Roland 3D Plotter (MDX-20, UK).

The tensile properties were determined using a Universal tensile machine (Instron 4505 Universal Machine, USA) with a load cell of $1 \mathrm{kN}$ and a gauge length of $25 \mathrm{~mm}$ and a crosshead speed of $5 \mathrm{~mm} \mathrm{~min}{ }^{-1}$. Samples were conditioned at room temperature for at least $48 \mathrm{~h}$ before testing and it was used 9 specimens per condition. The tensile force was taken as the maximum force in the force deformation curve. Tensile modulus was estimated from the initial slope of the stress-strain curve (between $0.05 \%$ and $0.25 \%$ strain) using linear regression. The normality of the distribution of the mechanical results was evaluated using the Shapiro-WilK test confirming their normal distribution at $p<0.05$. The results were compared using one-way analysis of variance (ANOVA) with the post hoc Bonferroni multiple comparison tests to infer about the significant differences between mean values of the developed functionalized composites and the differences were considered significantly different at $p<0.05\left({ }^{*}\right)$.

\subsection{Dimensional stability}

Measurements of water absorption and thickness swelling were made according to ASTM D 570 on the specimens used for tensile testing, after vacuum-drying at $70{ }^{\circ} \mathrm{C}$ and stabilization in a desiccator. Each specimen was immersed in distilled water, at ambient temperature, in falcon tubes of $14 \mathrm{ml}$ for different time periods (up to 15 days). At the end of each period, five specimens of each condition were gently blotted with absorbent paper to remove the excess water on the surface, immediately reweighed and their thickness measured using a digital micrometre from Mitutoyo (Japan) $( \pm 0.001 \mathrm{~mm})$, and then re-immersed. Water absorption $(W A)$ was calculated as:

$W A(\%)=\frac{W_{a}-W_{b}}{W_{b}} \times 100$

where $W_{a}$ and $W_{b}$ are the weights ( $\mathrm{g}$ ) after and before immersion, respectively. The thickness swelling (TS) is given by:

$\operatorname{TS}(\%)=\frac{T_{2}-T_{1}}{T_{1}} \times 100$

where $T_{2}$ is the thickness of the wetted specimen and $T_{1}$ is the initial thickness. Five specimens per condition were measured. 


\section{Results and discussion}

\subsection{Chemical characterisation}

The FTIR spectrum of cork presented in Fig. 3 is dominated by the presence of absorption bands for hydroxyl $\left(3400 \mathrm{~cm}^{-1}\right)$, methylene $\left(2920,2850\right.$ and $1452 \mathrm{~cm}^{-1}$ ) and ester $(1736,1240$ and $1150 \mathrm{~cm}^{-1}$ ) groups. The absorption band at $1508 \mathrm{~cm}^{-1}$ is associated with the vibration of the aromatic skeleton. This is consistent with the existence of highly suberized cell walls characteristic of cork. The spectrum of suberin is similar to that of cork, retaining essentially the absorption bands related to the aliphatic ester moieties. Therefore, the suberin obtained by extraction probably has its constitutive aliphatic monomers transesterified or in oligomeric blocks arising from incomplete depolymerization. The lignin spectrum presents an intense band at $3400 \mathrm{~cm}^{-1}$ due to hydroxyl groups, together with a shoulder at around $2570 \mathrm{~cm}^{-1}$. This configuration, in combination with the absorption band at $1714 \mathrm{~cm}^{-1}$, is consistent with the presence of carboxylic acid groups; the relatively intense 1610 and $1505 \mathrm{~cm}^{-1}$ bands are related to the presence of aromatic structures.

In summary, lignin and suberin partially retain the original cork structures. The aliphatic esterified domain is represented in suberin, whereas the aromatic domain in present in lignin.

\subsection{Thermal properties}

\subsubsection{Cork, suberin and lignin}

The thermogravimetric curves of cork and of its chemical fractions under air atmosphere obtained before compounding are represented in Fig. 4 in terms of weight loss and its derivative. A multi-step degradation process is evident. Cork and lignin show some weight reduction between room temperature and $150{ }^{\circ} \mathrm{C}$, due to the loss of water molecules (suberin is hydrophobic). The thermal degradation of cork starts at approximately at $270{ }^{\circ} \mathrm{C}$, with the first intensive weight loss at $\sim 348{ }^{\circ} \mathrm{C}$ and a second important region at circa $460{ }^{\circ} \mathrm{C}$ (Fig. 4b). This pattern should correspond to the degradation of the major cork components. The derivative curves of the isolated cork fractions demonstrate that the thermal decomposition of suberin and lignin occur independently. Suberin displays good thermal stability up to around $259^{\circ} \mathrm{C}$, followed by a progressive weight loss, reaching nearly $45 \%$ at $338{ }^{\circ} \mathrm{C}$ and $87 \%$ at $494{ }^{\circ} \mathrm{C}$. Lignin shows a small shoulder at $193{ }^{\circ} \mathrm{C}$, a low temperature when compared with cork and suberin, probably due to the monomeric structures of lignin resulting from extraction. Its maximum

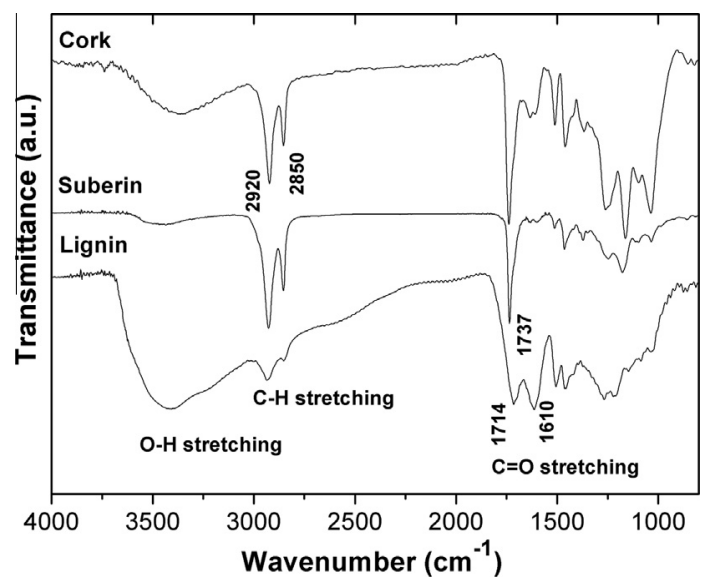

Fig. 3. ATR-FTIR spectra of cork and its major chemical isolated components used as coupling agent.
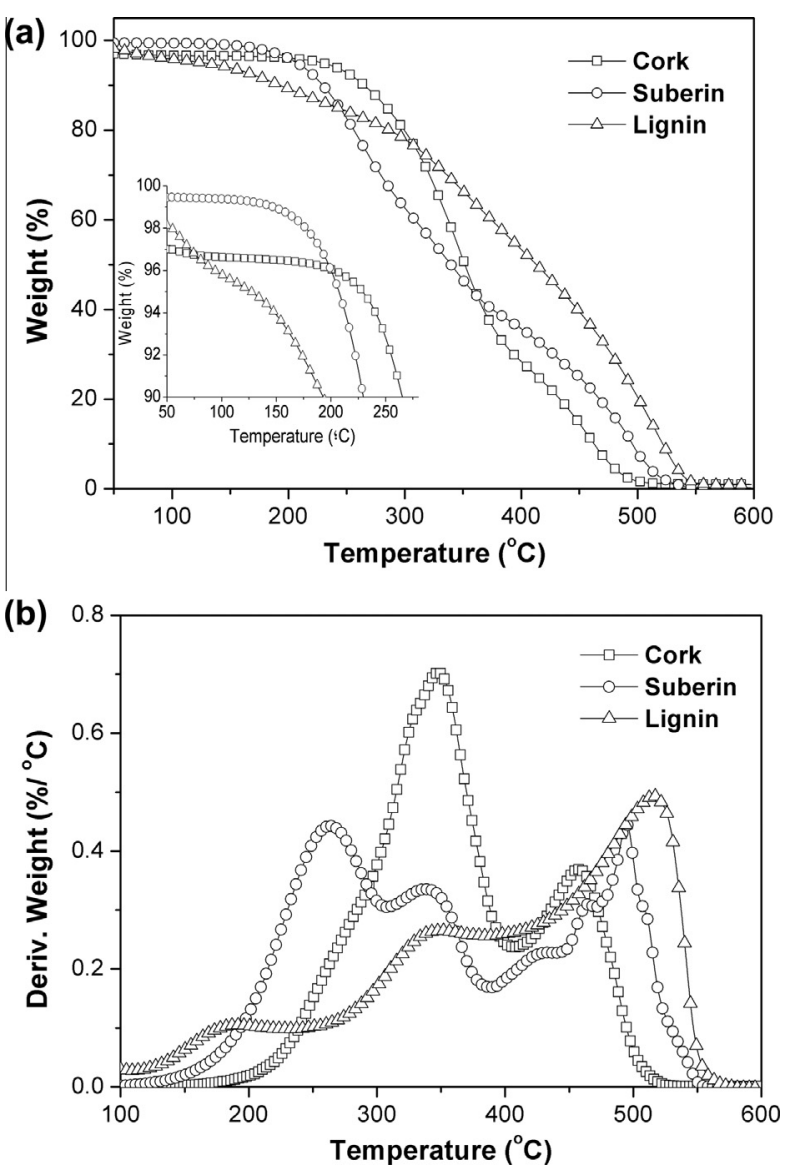

Fig. 4. Thermogravimetric curves of cork and the principal chemical components under air atmosphere (a) and respective derivative curves (b)

decomposition takes place at about $515^{\circ} \mathrm{C}$, confirming the higher thermal resistance as compared with suberin. At higher temperatures, the isolated cork fractions seem to present higher thermal stability. However, at $600{ }^{\circ} \mathrm{C}$ no char weight residue was detected.

\subsubsection{Composites and polymer matrix}

The main features from the thermogravimetric analysis of the composites and its polymeric matrix under air atmosphere are identified in Table 2 . In all cases, the onset of degradation was higher than $265{ }^{\circ} \mathrm{C}$ and the ash content was less than $0.3 \%$ at $600^{\circ} \mathrm{C}$. Although the HDPE matrix contains a thermal stabilizer, the addition of PE-g-MA and of $4 \mathrm{wt} . \%$ of lignin seems to have acted as a thermal protective barrier to cork, enhancing the thermal stability up to temperatures as high as $387-395^{\circ} \mathrm{C}$. This characteristic agrees well with the curves of Fig. 4, where lignin showed higher

Table 2

Initial degradation temperatures obtained by TGA, of the HDPE matrix, CPC in the presence and absence of suberin and lignin, and the coupling agent (PE-g-MA).

\begin{tabular}{lllll}
\hline & TGA & & & DTG \\
Sample & $T_{\max 1}\left({ }^{\circ} \mathrm{C}\right)$ & $T_{\max 2}\left({ }^{\circ} \mathrm{C}\right)$ & Ash content ${ }^{\mathrm{a}}(\mathrm{wt} . \%)$ & $T_{\max 1}\left({ }^{\circ} \mathrm{C}\right)$ \\
\hline HDPE & 274.0 & 374.5 & 0.10 & 358.4 \\
CPC 1 & 273.7 & 387.2 & 0.25 & 399.8 \\
CPC 2 & 276.1 & 391.1 & 0.29 & 404.3 \\
CPC 3 & 272.3 & 384.0 & 0.25 & 389.7 \\
CPC 4 & 267.0 & 386.0 & 0.26 & 391.0 \\
CPC 5 & 268.6 & 394.7 & 0.29 & 396.8 \\
\hline
\end{tabular}

$T_{\max 1}\left({ }^{\circ} \mathrm{C}\right)$ - First weight loss process

a Ash weight content at $600^{\circ} \mathrm{C}$. 
Table 3

Melting temperatures and enthalpies, crystallization temperatures, crystallinity degrees and oxidation induction times of CPC composites with HDPE as matrix.

\begin{tabular}{|c|c|c|c|c|c|c|}
\hline Sample & $T_{c \text { onset }}{ }^{\mathrm{a}}\left({ }^{\circ} \mathrm{C}\right)$ & $\Delta H_{c}^{\mathrm{a}}(\mathrm{J} / \mathrm{g})$ & $T_{m}{ }^{\mathrm{b}}$ onset $\left({ }^{\circ} \mathrm{C}\right)$ & $\Delta H_{m}^{\mathrm{b}}(\mathrm{J} / \mathrm{g})$ & $\chi_{c}{ }^{\mathrm{c}}(\%)$ & OIT (min) \\
\hline HDPE & 118.8 & 226.0 & 125.7 & 223.5 & 76.3 & $119.4 \pm 0.5$ \\
\hline CPC 1 & 121.9 & 188.3 & 126.2 & 185.7 & 79.2 & $60.4 \pm 1.0$ \\
\hline СРС 2 & 122.0 & 188.2 & 124.5 & 185.4 & 80.7 & $70.7 \pm 1.2$ \\
\hline CPC 3 & 123.2 & 173.9 & 125.5 & 172.0 & 75.6 & $74.4 \pm 0.2$ \\
\hline СРС 4 & 123.3 & 167.8 & 123.9 & 166.3 & 73.1 & $59.9 \pm 1.6$ \\
\hline CPC 5 & 123.2 & 163.0 & 124.2 & 161.6 & 72.6 & $54.9 \pm 0.7$ \\
\hline СРС 7 & 123.3 & 170.4 & 124.8 & 169.3 & 73.0 & $65.8 \pm 0.5$ \\
\hline
\end{tabular}

OIT (min) - oxidation induction time determined under pure oxygen.

a Crystallization temperature and enthalpy at second cooling from the melt at $10{ }^{\circ} \mathrm{Cmm}^{-1}$.

${ }^{b}$ Melting temperature and variation of enthalpy determined by DSC on the second heating at $10^{\circ} \mathrm{C} \mathrm{mm}^{-1}$.

c Crystallinity degree calculated on the basis of a $100 \%$ crystalline PE a melting enthalpy of $\Delta H_{m^{\circ}}=293 \mathrm{~J} / \mathrm{g}[33]$.

thermal resistance. Thus, lignin could be eventually used as a flame retardant. The derivative thermogravimetric (DTG) maximum values in Table 2, shows that under oxidative atmosphere and at higher temperatures the polymeric matrix decomposes more fast than the cork-polymer composites (CPC), being $358^{\circ} \mathrm{C}$ for the HDPE and $390{ }^{\circ} \mathrm{C}$ up to $404^{\circ} \mathrm{C}$ for the CPC. Cork confers thermal protection to the thermoplastic matrix at higher temperatures.

Table 3 lists the melting temperature $\left(T_{m}\right)$, crystallization temperature $\left(T_{c}\right)$, enthalpy $(\Delta H)$ and degree of crystallinity $\left(X_{c}\right)$ of the neat polymer and composites, as determined from DSC curves. The results show a slight increment of $T_{c}$ and degree of crystallinity for composites CPC 1 and CPC 2, indicating that the presence of cork promotes crystallization. This nucleating ability of cork has been previously observed [6]. No significant changes in the $T_{m}$ of the composites were detected. The composites containing suberin and lignin revealed lower melting enthalpy and crystallinity, probably due to BPO modification, which induces the formation of macroradicals that may produce branching and chain extensions [34].

Oxidative induction time (OIT) measurements were performed at $200{ }^{\circ} \mathrm{C}$ to compare the oxidation of the composites and analyse the effect of the proposed eco-friendly coupling agents. Table 3 , shows high values of OIT for all tested composites due to the use of HDPE grade with thermal stabilizer. Significant differences in the onset decomposition time of the exothermic reactions were found, with the OIT varying from 54.2 to $74.6 \mathrm{~min}$. It was found that the use of 2 wt.\% of lignin CPC 4 , does not influence significantly the thermal-oxidative stability of the composites under the isothermal conditions. However, the increase to $4 \mathrm{wt}$.\% of lignin CPC 5, results in a reduction of the OIT. In despite of the reduction of the polymer \%, the overall decrease of OIT is moderated by the presence of lignin. The phenolic groups in the lignin can impart antioxidant properties which provide stability to the polymer against thermal- and photo-oxidation [35]. The clear increase on the OIT for the compositions with PE-g-MA (CPC 2) and containing 2 wt.\% of suberin (CPC 3), is an indication that both substances may act and can be used as antioxidant on the composites. It is speculated that the existing aromatic domains of suberin contain various substituted phenolic groups [36], that may function as antioxidant.

\subsection{Morphology}

\subsubsection{Morphology evolution during compounding}

The morphology evolution during the twin-screw extrusion (TSE) process of the principal compositions after cryogenic fracture is presented in Fig. 5. The zone B location corresponds to the intensive mixing zone of the TSE. Composite samples were collected rapidly at specific barrel locations with a special sampling device. It can be observed the high distributive mixing capacity during the melting of the co-rotating TSE: the cork particles are well distributed and dispersed in the polymer matrix upstream the die zone, in particular for the CPC 2 to CPC 7 compositions. This result demon- strates: (a) the importance of intensive mixing zones in the screw configuration to promote the efficient mixing of the monomer with the polymer, in this case a block of 4 kneading disks with a staggering angle $-30^{\circ}$ and (b) highlights the importance of the coupling agent based on PE-g-MA, suberin or lignin to promote dispersion of the natural phase. Moreover, micro voids on the morphology were observed, in particular in the compositions using BPO. A proper venting design with vacuum or an efficient devolatilization system on the extruder may be necessary to eliminate the entrapped gas and the residual products generated during the reactive extrusion process. In addition, at high magnification the obtained extruded CPC pellets present good linkage between the cork and the HDPE independently of the processed composition and the presence of micro pores in the structure was considerably reduced.

\subsubsection{Morphology of composites}

The composites present good aesthetic characteristics with a homogeneous visual distribution of cork. Fig. 2a) shows the visual aspect of a flexible extruded composition with $2 \mathrm{wt} . \%$ of suberin. The composite pellets containing lignin, presented in Fig. 2b), have a more intense brown colour with well dispersed lignin.

The fracture morphology of the composites after tensile tests is presented in Fig. 6. The tensile fracture of the unreinforced CPC is presented in Fig. 6b) and reveals high stretched elements of HDPE between the cork particles. Fig. $6 c$ and d) shows the influence of the addition of PE-g-MA with the fracture occurring at the same level of the cork and the polymeric matrix, supporting the indication of good adhesion. Both results are in agreement with previous works using melt based technologies such as pultrusion and extrusion to produce cork based composites [7,22]. The morphology of CPC 4 using 2 wt.\% of lignin presents similar fracture as compared with the composite using PE-g-MA. The composites with 2 wt.\% of suberin in Fig. 6f) two distinct zones of the polymeric phase can be observed: (i) a small portion of the polymeric matrix is stretched, probably due to the presence of suberin which is promoting additional ductility, also observed at lower magnification in Fig. 6e) and (ii) a fracture zone that occurs at the same level than cork phase due to the presence of the BPO. Moreover, during the extrusion process the visual aspect of the extruded composite surface containing suberin was smoother, reducing the shear during the extrusion. This effect may be related with a plasticizer capacity of suberin composed of esterified monomers and oligomers [11]. Additionally, we did not observe the presence of micro-voids on the different composites fracture, probably due to the temperature and pressure applied during the compression moulding to produce the composite plaques.

\subsection{Mechanical properties}

The maximum tensile strength and the tensile modulus of the developed cork-polymer composites are presented in Fig. 7. The 

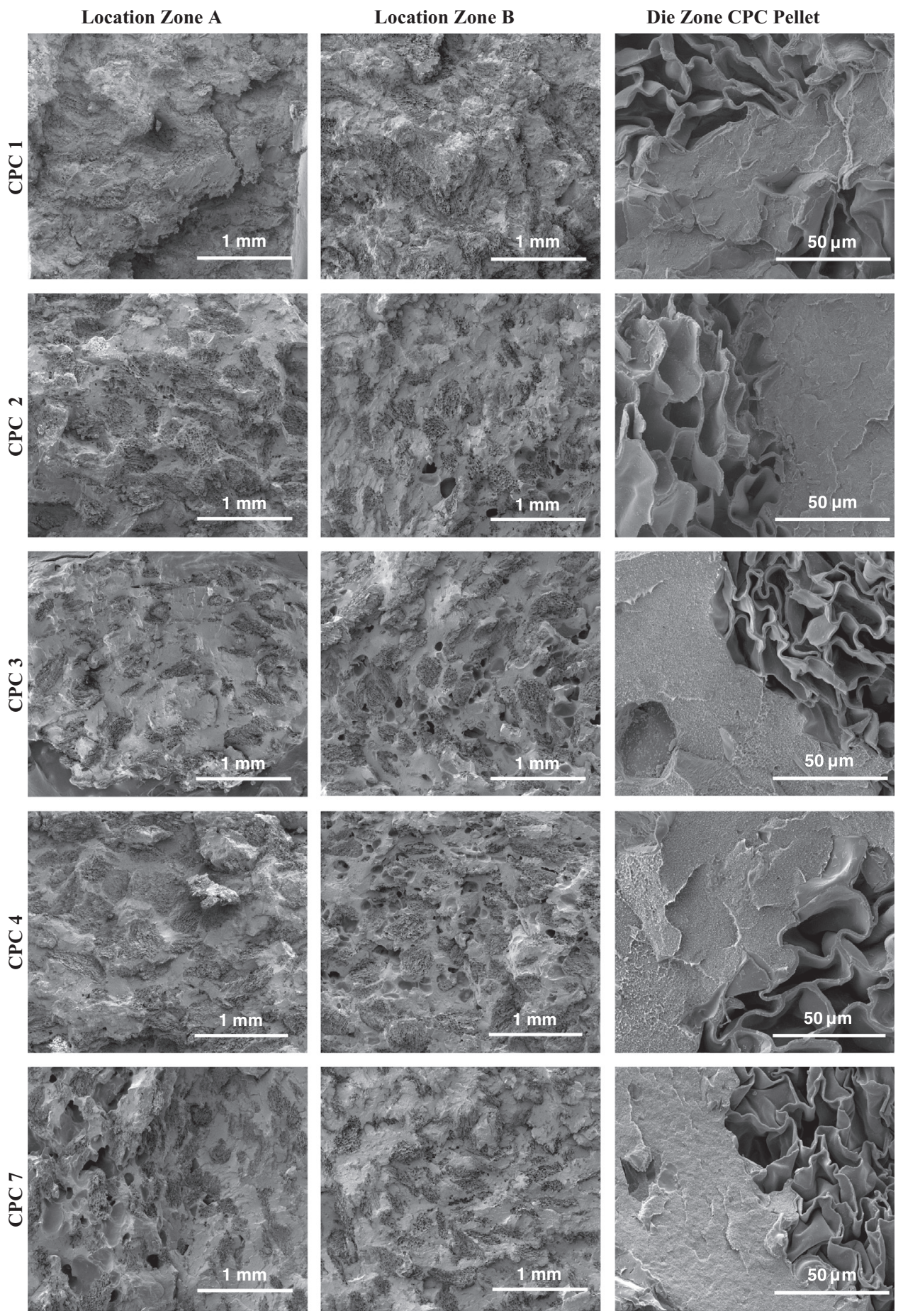

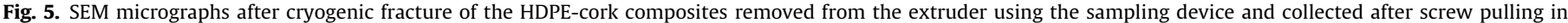
locations (A and B) and at the die at magnifications of $\times 100$ and $\times 2400$.

dashed line in the graphic represents the effect of BPO on the maximum tensile strength. Moreover, Fig. 8 depicts summarised the mean variation (\%) of the tensile properties, including the maximum strain, were the significant differences between samples are compared with the unreinforced cork-polymer composite CPC 1. It can be clearly observed from Fig. 8 a) that the use of a coupling agent based on maleic anhydride (MA) considerably increases both strength and modulus of the materials and reduces the maximum strain as shown in Fig. 8b). The MA may interact with the polar groups of cork (mainly hydroxyl groups $(-\mathrm{OH})$ ) of lignin and hemicellulose to form covalent or hydrogen bonding, providing chemical affinity and strong adhesion at the interface. The use of the $\mathrm{BPO}$ is represented in $\mathrm{CPC} 7$, showed to act as a coupling agent without a negative effect on the maximum strain. During the extrusion process, BPO may initiate radicals which react with the cork surface and the polymeric matrix, promoting chemical bonding between the two phases. In the literature [37], it is referred that the grafting of peroxide radicals onto polyethylene could take place though an attack on the tertiary carbons and on the few double bonds present in the backbone chain. Alternatively, the combination of peroxide groups and high temperatures could introduce polarity in the polymer, thereby increasing the adhesion at 

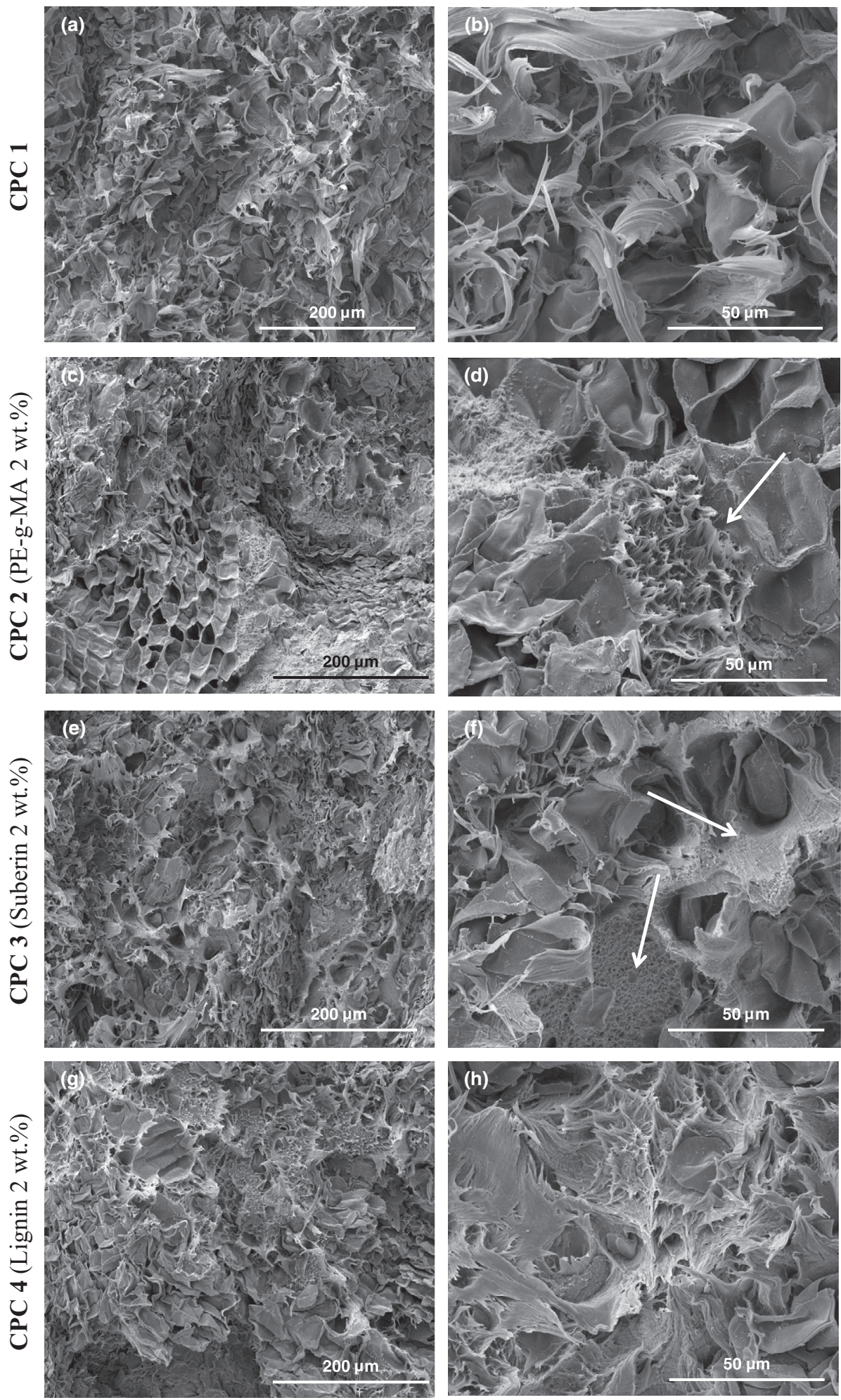

Fig. 6. SEM pictures of cross-sectional fractured surfaces after tensile tests of the cork reinforced composites at magnifications $\times 600$ and $\times 2400$.

polymer-fibre contacts [37]. Due to the chemical nature of cork, it is speculated that a similar action process can occur during the processing of the developed composites, resulting in an enhancement on the mechanical performance. In the functionalized CPC, the addition of $2 \mathrm{wt}$.\% of suberin promoted an increase of the maximum tensile strength, modulus and maximum strain comparing with the unreinforced CPC 1 . However and comparing with the CPC 7, the real effect of improvement was observed for the maximum strain with an increasing of $6.7 \%$. It seems that suberin can act as plasticizer agent during the extrusion process, reducing the stiffness and contributing with some additional flexibility to the composite material. This effect of suberin on the composites resembles in part its function on the cork material, being responsible for the elasticity on the cork material [9]. Moreover, glycerol is the principal monomer of suberin [16], which is used as plasticizer on composite systems $[38,39]$. The challenge on the production of 


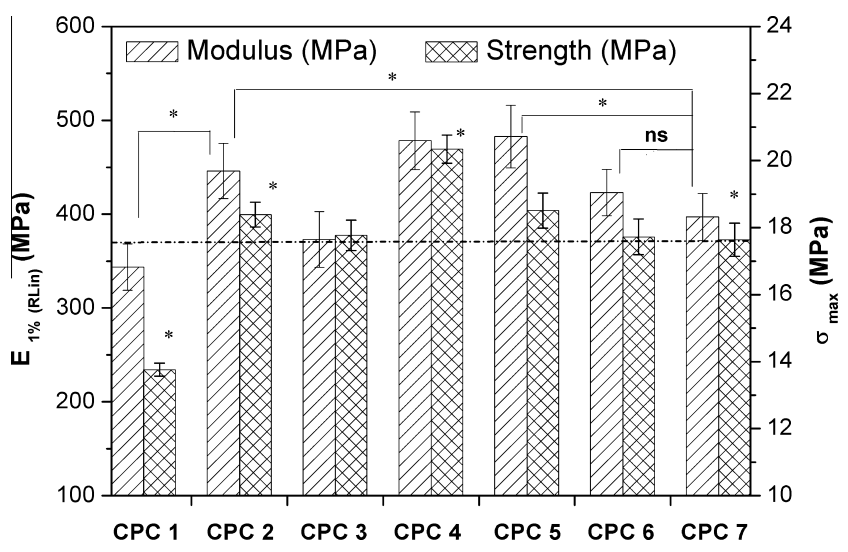

Fig. 7. Tensile properties of the developed functionalized cork composites. $\left(^{*}\right)$ Significant at 0.05 ; ns: non-significant at 0.05 .
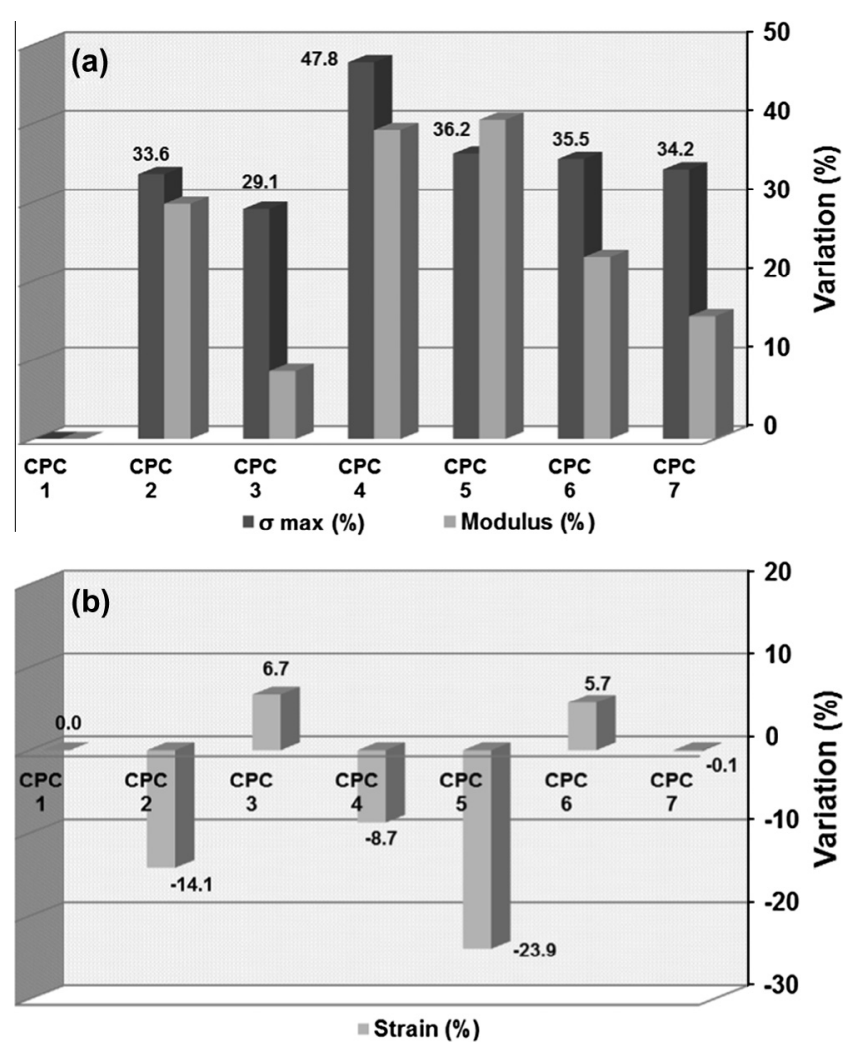

Fig. 8. Variation of the tensile properties being the control CPC 1, where (a) indicates the variation of maximum tensile strength and modulus and (b) the variation of maximum strain at break.

CPC with a high cork content using extrusion is the poor processability of the components, which may result in inadequate properties of the resulting composite. The use of suberin acting as biobased plasticizer can reduce the high friction created by the cork, reducing the shear during the extrusion process.

Surprisingly, the introduction of $2 \mathrm{wt}$ \% of lignin in the presence of BPO (CPC 4) increased the maximum tensile strength in $48 \%$ and the tensile modulus in $39 \%$ and decreased the maximum strain. The result confirms the high effectiveness of lignin as coupling agent, improving the interfacial adhesion and providing stress transfer from the matrix to the natural filler. The function of lignin as coupling agent is enabled by the presence of both aliphatic and polar hydroxyl groups, which provide compatibility between nonpolar polymers and lignocellulosic materials [26,27,40], such as cork. The increase of the lignin content (CPC 5) does not contribute to an additional increase on the mechanical performance. On the contrary, it results on a reduction of the maximum tensile strength. On the other hand, we also found that the feeding of lignin in the hopper system of the extruder (CPC 6) is not so effective to promote strength but increases the maximum tensile strain. Probably, the higher residence time of the lignin in the extruder promoted a better dispersion of lignin and consequently of cork phase in the polyethylene matrix increasing the maximum strain in $5.7 \%$. The unreinforced composite with $20 \mathrm{wt}$.\% of cork (CPC1) presents lower mechanical properties when comparing with the high density polyethylene (HDPE) matrix, being $407.2 \pm 19.9 \mathrm{MPa}$ in terms of tensile modulus and $25.1 \pm 0.5 \mathrm{MPa}$ of maximum strength for the HDPE matrix. Moreover and based on these mechanical values, the functionalization strategy by using lignin promoted an increase in the composite stiffness reinforcing the HDPE matrix. However the maximum tensile strength of the composites does not reach the matrix value.

\subsection{Dimensional stability}

After processing, the moisture content of the developed composite specimens was determined, being the highest for CPC 1 , with $0.313 \pm 0.004 \%$, and the lowest for CPC 3, with $0.276 \pm 0.011 \%$, corresponding to the functionalized composite with suberin. The functionalized CPC with the addition of lignin (CPC 4) presented $0.291 \pm 0.009 \%$ of moisture content.

The water uptake behaviour of the different CPC was examined as a function of the time see in Fig. 9. In the absence of coupling agent a faster water uptake was observed when compared with the functionalized composites due to the hydroxyl groups from cork which are available for interaction with water molecules. Even for the maximum period of immersion studied $(360 \mathrm{~h})$, the water uptake for the composites was inferior to $1.7 \%$, which is a clear advantageous property for many applications. The use of coupling agent significantly reduces the water absorption of the developed composites. The specimens with suberin and lignin absorb less water comparing with the unreinforced cork-polymer composition. In the firsts $24 \mathrm{~h}$ of immersion in water the CPC 1 absorbed $0.59 \pm 0.06$ wt.\% of water while the CPC 3 containing 2 wt.\% of suberin only absorbs $0.40 \pm 0.02 \mathrm{wt} . \%$. This difference is more evident after the 7 days of immersion were the CPC 3 absorbs less 32.5\% of water comparing with the condition of the CPC 1 and less $66.3 \%$ comparing with the composite containing $2 \mathrm{wt} . \%$ of lignin

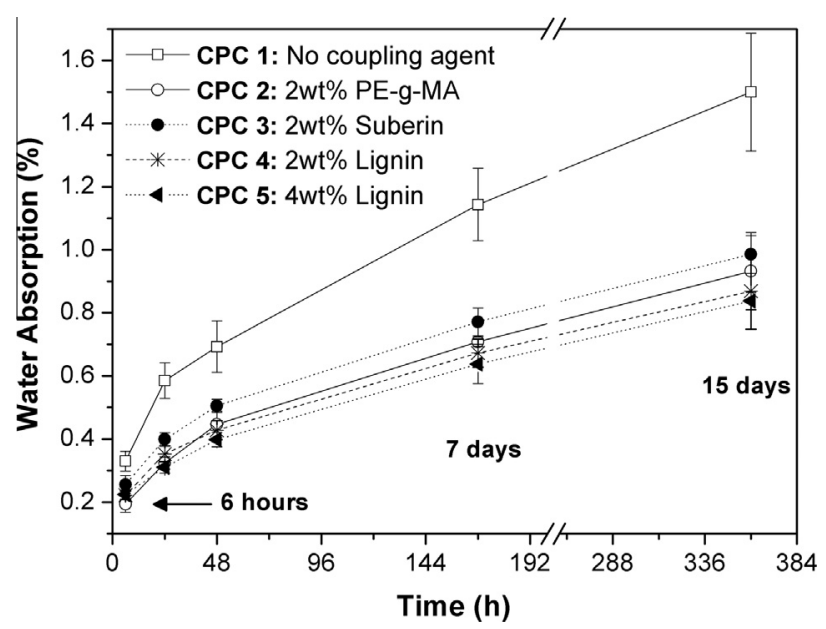

Fig. 9. Water absorption behaviour of the HDPE-cork composites with and without coupling agent, being PE-g-MA the coupling agent based on maleic anhydride. 


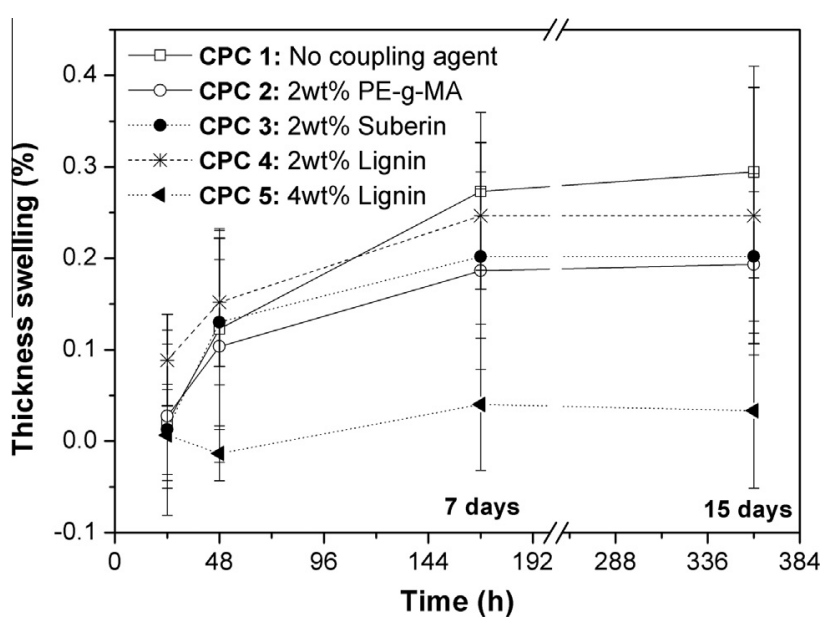

Fig. 10. Thickness swelling variation of the functionalized CPC comparing with the control condition (CPC 1) with HDPE-cork (80-20) wt.\%, being PE-g-MA the coupling agent based on maleic anhydride.

(CPC 4). This result supports the idea that suberin and lignin can act as coupling agent, reducing the moisture content and the water absorption of the CPC in a similar way to what was observed for the composite containing PE-g-MA. Moreover, suberin has a hydrophobic character that contributes to the low permeability of cork [4]. The addition of $1 \mathrm{wt} . \%$ of benzoyl peroxide could also be responsible to react with some hydroxyl groups from the cork structure, further contributing to reducing the water absorption.

The thickness swelling variation for all the composites was less than $0.4 \%$ as presented in Fig. 10 . It was observed that the coupling agent effect promotes less thickness variation. Increasing the lignin content (CPC 5), leads to a lower thickness variation. For the functionalized CPC and after the period of 15 days the thickness swelling variation tends to stabilize.

\section{Conclusions}

The following conclusions can be drawn base on the results presented in this work. Suberin and lignin fractions, isolated from cork, presents sufficient thermal stability to be applied in melt based technologies such as extrusion and compression moulding. A reactive twin-screw extrusion process was used to obtain the cork-polymer composites (CPC) in a continuous process. The mechanical tensile tests indicated that the suberin and lignin can be successfully used as bio-based coupling agents in the presence of benzoyl peroxide (BPO) to produce functionalized CPC with superior mechanical properties. Preferably, suberin acts as a plasticizer, improving the cork dispersion and reduces the composite stiffness, providing additional flexibility and formability to the composite. Lignin shows to act as a coupling agent and the use of $2 \mathrm{wt} . \%$ of lignin improved both maximum tensile strength and modulus in $48 \%$ and $39 \%$ respectively. Increasing the amount of lignin to $4 \mathrm{wt}$.\% reduces the mechanical performance of the composites. The extrusion process shows that the addition of lignin in the feed hopper of the extruder is not advantageous and only increases the maximum tensile strain. The tensile tests also reveal that the use of $2 \mathrm{wt} . \%$ of PE-g-MA increases 34\% the maximum strength, $30 \%$ the tensile modulus and reduces the maximum strain. Coupling agents in CPCs play a very important role in improving compatibility and adhesion between the polar cork material and the non-polar polymer matrices. The CPCs present low water uptake and thickness swelling variation. The use of coupling agent based on maleic anhydride or by adding suberin or lignin further reduces considerably the water uptake of the composites. The thermal properties showed that lignin can act as a thermal protective agent and suberin act as an antioxidant agent on the composites, while the PE-g-MA act as both. Coupling agents obtained from renewable resources may constitute a viable alternative to existing petroleum derivatives, contributing for a sustainable development of structural materials.

\section{Acknowledgments}

The work was performed within the project of Corticeira Amorim S.G.P.S. on the development of new products based in/with cork. The authors gratefully acknowledge the financial support, through the COMPETE/QREN/EU funding program in the project with acronym NovelComp (QREN FCOMP-01-0202-FEDER003107). The authors acknowledge the Portuguese Foundation for Science and Technology (FCT) and POPH/FSE for the doctoral Grants to E.M.F. (SFRH/BD/71561/2010) and I.M.A. (SFRH/BD/ 42273/2007).

\section{References}

[1] Faruk O, Bledzki AK, Fink H-P, Sain M. Biocomposites reinforced with natural fibers: 2000-2010. Prog Polym Sci 2012;37(11):1552-96.

[2] Dittenber DB, GangaRao HVS. Critical review of recent publications on use of natural composites in infrastructure. Composites Part A 2012;43(8):1419-29.

[3] Ku H, Wang H, Pattarachaiyakoop N, Trada M. A review on the tensile properties of natural fiber reinforced polymer composites. Compos Part B Eng 2011;42(4):856-73.

[4] Pereira H. Cork: biology, production and uses. Amsterdam: Elsevier; 2007.

[5] El-Sabbagh A. Effect of coupling agent on natural fibre in natural fibre/ polypropylene composites on mechanical and thermal behaviour. Compos Part B - Eng 2014;57:126-35.

[6] Fernandes EM, Correlo VM, Chagas JAM, Mano JF, Reis RL. Cork based composites using polyolefin's as matrix: morphology and mechanical performance. Compos Sci Technol 2010;70(16):2310-8.

[7] Fernandes EM, Correlo VM, Mano JF, Reis RL. Novel cork-polymer composites reinforced with short natural coconut fibres: effect of fibre loading and coupling agent addition. Compos Sci Technol 2013;78:56-62.

[8] Fernandes EM, Correlo VM, Chagas JAM, Mano JF, Reis RL. Properties of new cork-polymer composites: advantages and drawbacks as compared with commercially available fibreboard materials. Compos Struct 2011;93(12):3120-9.

[9] Silva SP, Sabino MA, Fernandes EM, Correlo VM, Boesel LF, Reis RL. Cork: properties, capabilities and applications. Int Mater Rev 2005;50(6):345-65.

[10] Mano JF. The viscoelastic properties of cork. J Mater Sci 2002;37(2):257-63.

[11] Koskimies S, Hulkko J, Pitkaenen P, Heiskanen N, Yli-Kauhaluoma J, Waehaelae $\mathrm{K}$ et al. Method for the manufacture of oligo- and polyesters from a mixture of carboxylic acids obtained from suberin and/or cutin and the use thereof. W02007045728-A1. Valtion Teknillinen Tutkimuskeskus; 2007.

[12] Santos S, Graca J. Glycerol-omega-hydroxyacid-ferulic acid oligomers in cork suberin structure. Holzforschung 2006;60(2):171-7.

[13] Graca J, Santos S. Linear aliphatic dimeric esters from cork suberin. Biomacromolecules 2006;7(6):2003-10.

[14] Cordeiro N, Belgacem MN, Silvestre AJD, Neto CP, Gandini A. Cork suberin as a new source of chemicals. 1. Isolation and chemical characterization of its composition. Int J Biol Macromol 1998;22(2):71-80.

[15] Bernards MA. Demystifying suberin. Can J Bot 2002;80(3):227-40.

[16] Graca J, Pereira H. Methanolysis of bark suberins: analysis of glycerol and acid monomers. Phytochem Anal 2000;11(1):45-51.

[17] Graca J, Pereira H. Feruloyl esters of omega-hydroxyacids in cork suberin. J Wood Chem Technol 1998;18(2):207-17.

[18] Marques AV, Pereira H, Meier D, Faix O. Quantitative-analysis of cork (QuercusSuber L) and milled cork lignin by FTIR spectroscopy, analytical pyrolysis, and total hydrolysis. Holzforschung 1994;48:43-50.

[19] Marques AV, Pereira H, Meier D. Isolation and characterization of a guaiacyl lignin from saponified cork of Quercus suber L. Holzforschung 1996;50(5):393-400.

[20] Marques AV, Pereira H, Meier D, Faix O. Structural characterization of cork lignin by thioacidolysis and permanganate oxidation. Holzforschung 1999;53(2):167-74.

[21] Xanthos M. Reactive extrusion: principles and practice. Hanser Publishers Oxford University Press; 1992.

[22] Fernandes EM, Aroso I, Pires RA, Correlo VM, Pitkänen P, Koskimies S, Mano JF, Reis RL. Improvement on the mechanical properties of cork composites using suberin as coupling agent through a reactive extrusion process. In: ANTEC 2011, annual technical conference of the society of plastics engineeres (SPE), vol. 1. Boston (MA); 2011. p. 611-5.

[23] Sahoo S, Misra M, Mohanty AK. Enhanced properties of lignin-based biodegradable polymer composites using injection moulding process. Composites Part A 2011;42(11):1710-8. 
[24] Kharade AY, Kale DD. Lignin-filled polyolefins. J Appl Polym Sci 1999;72(10):1321-6.

[25] Wood BM, Coles SR, Maggs S, Meredith J, Kirwan K. Use of lignin as a compatibiliser in hemp/epoxy composites. Compos Sci Technol 2011;71(16):1804-10.

[26] Rozman HD, Tan KW, Kumar RN, Abubakar A, Mohd. Ishak ZA, Ismail H. The effect of lignin as a compatibilizer on the physical properties of coconut fiberpolypropylene composites. Eur Polym J 2000;36(7):1483-94.

[27] Morandim-Giannetti AA, Agnelli JAM, Lancas BZ, Magnabosco R, Casarin SA, Bettini SHP. Lignin as additive in polypropylene/coir composites: thermal, mechanical and morphological properties. Carbohydr Polym 2012;87(4):2563-8.

[28] Moad G. The synthesis of polyolefin graft copolymers by reactive extrusion. Prog Polym Sci 1999;24(1):81-142.

[29] Ekman R, Eckerman C. Aliphatic carboxylic-acids from suberin in birch outer bark by hydrolysis, methanolysis, and alkali fusion. Pap Puu-Pap Tim 1985;67(4):255.

[30] Pinto PCRO, Sousa AF, Silvestre AJD, Neto CP, Gandini A, Eckerman C, et al. Quercus suber and Betula pendula outer barks as renewable sources of oleochemicals: a comparative study. Ind Crops Prod 2009;29(1):126-32.

[31] Browning BL. Methods in wood chemistry. New York: Interscience Publishers; 1967.
[32] Machado AV, Covas JA, Van Duin M. Evolution of morphology and of chemica conversion along the screw in a corotating twin-screw extruder. J Appl Polym Sci 1999;71(1):135-41.

[33] Wunderlich B, Dole M. Specific heat of synthetic high polymers. VIII. Low pressure polyethylene. J Polym Sci 1957;24(106):201-13.

[34] Pérez CJ, Cassano GA, Vallés EM, Failla MD, Quinzani LM. Rheological study of linear high density polyethylenes modified with organic peroxide. Polymer 2002;43(9):2711-20.

[35] Canetti M, Bertini F. Supermolecular structure and thermal properties of poly(ethylene terephthalate)/lignin composites. Compos Sci Technol 2007;67(15-16):3151-7.

[36] Gandini A, Pascoal Neto C, Silvestre AJD. Suberin: a promising renewable resource for novel macromolecular materials. Prog Polym Sci 2006;31(10):878-92.

[37] Cousin P, Bataille P, Schreiber HP, Sapieha S. Cellulose-induced crosslinking of polyethylene. J Appl Polym Sci 1989;37(10):3057-60.

[38] Cunha AM, Liu ZQ, Feng Y, Yi XS, Bernardo CA. Preparation, processing and characterization of biodegradable wood flour/starch-cellulose acetate compounds. J Mater Sci 2001:36(20):4903-9.

[39] Fernandes EG, Cinelli P, Chiellini E. Thermal behavior of composites based on poly(vinyl alcohol) and sugar cane bagasse. Macromol Symp 2004;218:231-9.

[40] Acha BA, Marcovich NE, Reboredo MM. Lignin in jute fabric-polypropylene composites. J Appl Polym Sci 2009;113(3):1480-7. 